\title{
Erratum: Relationship between MRI derived right ventricular mass and left ventricular involvement in patients with anderson-fabry disease
}

Ming-Yen Ng ${ }^{1,2^{*}}$, Qin Li ${ }^{1,3}$, Anna Calleja ${ }^{3}$, Djeven P Deva ${ }^{1,4}$, Andrew M Crean ${ }^{1,3}$, Christiane Gruner ${ }^{3}$, Robert M Iwanochko ${ }^{3}$ and Paaladinesh Thavendiranathan ${ }^{1}$

Following publication of this abstract [1] it was noted by the authors that an incorrect version of Figure 1 had been inadvertently uploaded with the manuscript. The correct version Figure 1 is available below.

In addition it was found that the author list was incorrectly ordered, this has been corrected in the author list above.
Received: 23 March 2015 Accepted: 23 March 2015

Published online: 29 May 2015

\section{Reference}

1. Li Q, Ng MY, Calleja A, Deva DP, Crean AM, Gruner C, et al. Relationship between MRI derived right ventricular mass and left ventricular involvement in patients with anderson-fabry disease. J Cardiovasc Magn Reson. 2015;17(Suppl 1):275

\section{Author details}

${ }^{1}$ Radiology, University of Toronto, Toronto, ON, Canada. ${ }^{2}$ Radiology, The University of Hong Kong, Hong Kong, Hong Kong. ${ }^{3}$ Cardiology, University of Toronto, Toronto, ON, Canada. ${ }^{4}$ Radiology, St. Michael's Hospital, Toronto, ON, Canada.

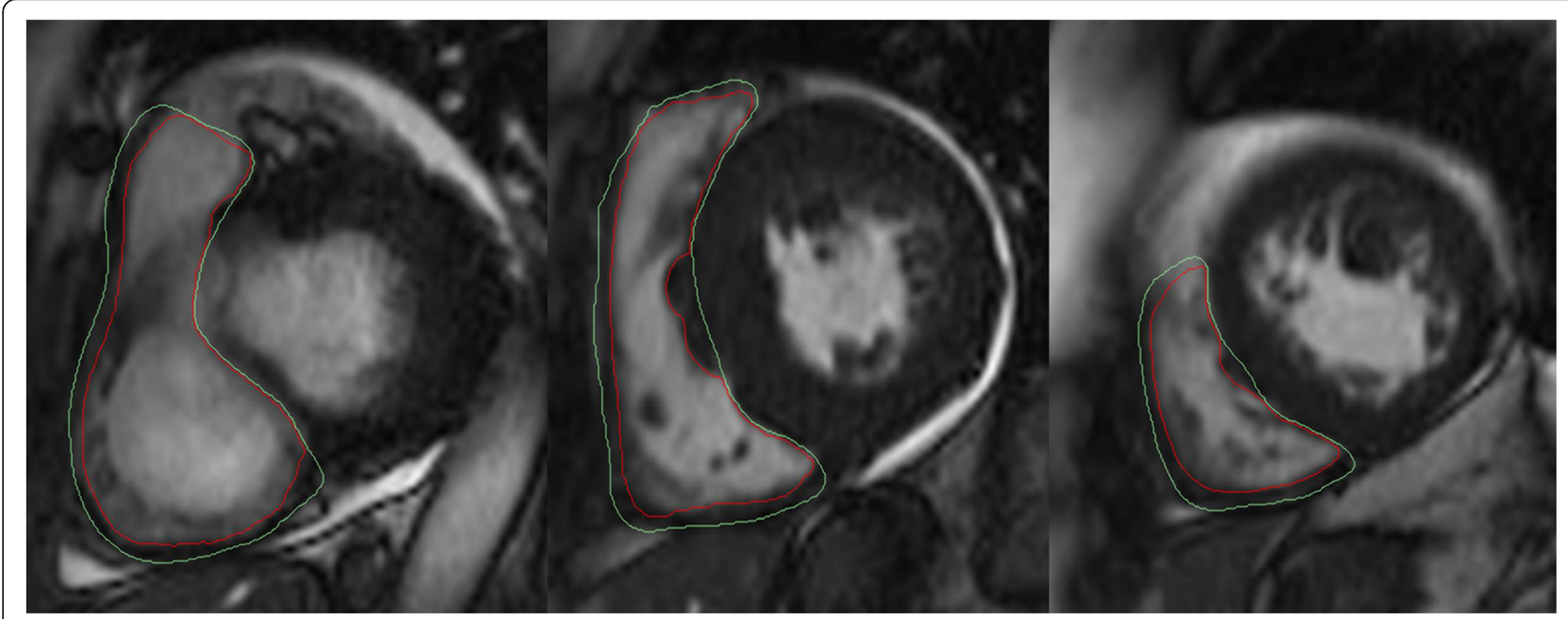

Figure 1 Assessment of RV volume, function, and mass using short axis SSFP cine images (CMR42). The RV septal band was included in the assessment of the RV mass.

\footnotetext{
* Correspondence: myng2@hku.hk

'Radiology, University of Toronto, Toronto, ON, Canada

${ }^{2}$ Radiology, The University of Hong Kong, Hong Kong, Hong Kong
}

\section{() Biomed Central}

(C) $2015 \mathrm{Ng}$ et al.; licensee BioMed Central. This is an Open Access article distributed under the terms of the Creative Commons Attribution License (http://creativecommons.org/licenses/by/4.0), which permits unrestricted use, distribution, and reproduction in any medium, provided the original work is properly credited. The Creative Commons Public Domain Dedication waiver (http://creativecommons.org/publicdomain/zero/1.0/) applies to the data made available in this article, unless otherwise stated. 